Discourse and Communication for Sustainable Education, vol. 11, no. 2, pp. 106-120, 2020

\title{
A Sustainable Way of Teaching Basic Mathematics
}

\author{
Anita Summer \\ University Teacher College, Vienna/Krems, Austria
}

\begin{abstract}
Quality primary education is one of the 17 UN Sustainable Development Goals (SDGs). Undoubtedly, mathematics plays a key role in overcoming future challenges, and mathematical competence and problem-solving skills could help provide appropriate solutions to current and future social, environmental and economic challenges. The following paper deals with Sustainability in Basic Mathematics Education as a great number of students experience anxiety in learning mathematics. The literature-based research text explores the following question: How should a sustainable primary education in mathematics be implemented and which concrete pedagogical initiatives need to be taken? The present article addresses why some students encounter challenges in learning mathematics at the beginning of their education in school. Moreover, it demonstrates how competent teaching could decrease students' difficulties and in learning mathematics.
\end{abstract}

Key words: sustainability, basic education in mathematics, primary school, didactics, teacher training, arithmetic difficulties, dyscalculia.

\section{The Role of Mathematics in Sustainable Education}

Preparing individuals for future challenges must start in primary school by giving them a solid foundation in mathematical skills and developing problem-solving and critical thinking skills in pupils. An innovative approach is needed to help pupils encounter everyday problems as well as to empower them to find novel and sustainable solutions for key challenges of the current world (Akinmola, 2014; Guseva et al., 2012; Gerretson et al., 2010).

To meet the demanding challenges of the future, society needs each and every one of us. At the summit of the United Nations (2015), the "Agenda 2030 for Sustainable Development" was adopted. All 193 member states of the United Nations committed themselves to working towards the implementation of Agenda 2030 with its 17 Sustainable Development Goals (SDGs) at national, regional and international level by 2030 . Education is an essential prerequisite for fulfilling the entire Agenda 2030. Consequently, education plays a key role in creating an equitable, peaceful, and sustainable society. The international community has set itself the goal "to ensure inclusive, equal and highquality education and to promote opportunities for lifelong learning for all” (BMBWF, 
2019). Goal Four demands high quality education: By 2030, it is expected that all female and male students complete free and high quality primary and secondary education on an equal footing, leading to useful and effective learning outcomes (Bka, 2015; BMBWF, 2019; Salīte \& Pipere, 2016).

This implies a clear mandate for teachers as well as for teacher education because "all entrepreneurs of the future are in school today, the nature of their value-oriented education and their willingness to participate is shaped by today's learning" (Lindner, 2019, p. 124).

The field of mathematics in particular plays a key role in meeting future challenges. Thanks to mathematics, "perceived correlations" can be turned into statistically validated correlations, or hypotheses could be rejected. Due to its universal acceptance, mathematics has the possibility to scientifically substantiate the debate on sustainable development and global sustainability and to structure complex processes in an understandable way. Mathematical competence and problem-solving skills form an essential basis for mastering future challenges.

Since decisions are made based on data in the contemporary era, it is important for learners to develop and strengthen skills in mathematics. These skills are essential for education and training and significantly affect future employability and career choices. Employers seek employees who are proficient in mathematics, because of their problemsolving skills. In addition to economic benefits, mathematics is also deemed as a tool to promote social values and democratic principles, such as equality and justice. On the one hand, democracy demands a means of communication and discussing principles in a rational way, and mathematics with its close relationship with rationality helps achieve democracy. On the other hand, democracy demands operational procedures for its concrete implementation, and mathematics also facilitates this (Safford-Ramus et al., 2016).

However, a great number of pupils find mathematics a highly challenging subject. At the beginning of their education in school mathematics is deemed as subject requiring a multitude of drills which is difficult for most of pupils to understand. This fact is supported by numerous studies: "Fear of mathematics is dominant compared to other subjects and joy is relatively seldom experienced. Overall, an unfavorable pattern is emerging for mathematics from an emotional perspective" (Götz, 2012, p. 2). The connection between fear of failure in mathematics and low achievement is confirmed especially for girls (Weber \& Petermann, 2016).

Adults often do not understand why some children find it difficult to take their "first steps" into mathematics or arithmetic. These children already fail in the basic range of numbers and therefore hardly gain a sustainable understanding of mathematics. Statements such as “why don't you understand this, it's quite logical. Strive harder, you can do it" (Selter, 2012, p. 1) are not only pedagogically useless, but also show that the difficulties and hurdles of the subject are not understood by adults.

It is difficult for children to make up for basic insights, and, as a result, learners often carry out procedures that they do not understand and give up on understanding content and exploring correlations. "They sometimes use formulas and algorithms that they do not understand and if they do not remember, they are not able to find solutions in other ways" (Schütky et al., 2017, p. IV). These children are deprived of a lot of interesting and necessary knowledge of mathematics and possibilities to apply problemsolving strategies as well as many career aspirations associated with this. In line with the "SDG four" or all SDGs, it must therefore be the goal of teachers to support children 
in acquiring sustainable basic mathematical skills following the children's train of thoughts and to accompany them in the acquisition of the first basic mathematical concepts, which comes with as much understanding as possible.

This article aims to answer the following research question on the basis of a literature analysis: How should a sustainable mathematical primary education be implemented and which concrete pedagogical initiatives need to be taken? It is shown how children with numeracy difficulties think. It will be presented that what seems so difficult to them in their initial mathematics lessons; and, above all, that these children are by no means stupid or unwilling, but use quite reasonable ways and structures of thinking. Furthermore, it will be demonstrated that didactic practices that have been in use for years can encourage the development of useless patterns of thought and explanation. In order to prevent possible arithmetic difficulties, a literature-driven approach is presented to show how initial mathematical instruction needs to be implemented in kindergarten and school. This requires a sound knowledge of possible hurdles and difficulties that may arise in mathematical lessons. However, it is by no means the author's intention to give "recipes"; at best, the ideas should be understood as possible alternatives for action, which have to be individually adapted to the learning process of each child. This paper does not claim that arithmetic difficulties or dyscalculia (i.e., a condition that affects the ability to acquire arithmetical skills) can be prevented in every single case, because dyscalculia is based on multi-causal factors. The teacher has no influence on many of them. Nonetheless, the aim of sustainable education in mathematics should certainly be to develop a deeper understanding of children with dyscalculia and to become aware of the pedagogical responsibility concerning the first mathematics lessons in order to make a significant contribution to fulfill the "SDG four" goals.

\section{Mathematics as a Living Science}

Mathematics is seen as a living science of patterns and structures. Teaching is not based on fixed structures, but on individual and social processes. Only these processes lead to mathematical knowledge. They are based on self-directed learning, and making mistakes is inevitable. Lessons should be drawn from these mistakes in the discussion with other learners, which is essential for learning. In line with the new concept of mathematics, currently learning is no longer understood as building a wall according to a given plan, strictly avoiding gaps, but as the continuous creating a net of elements of knowledge and skills" (Müller \& Wittmann, 2016, p. 158). A child has "understood" a mathematical concept or procedure when he/she has made connections with ideas that have already existed in his/her mind. The more numerous and stronger these connections are to already established nets, the more deeply the new content is anchored. It is therefore essential to establish links between different presentations, ideas and applications (Gerster \& Schulz, 2004).

While just a few decades ago the emphasis in lessons was on rapid and time-saving calculation procedures, a shift of paradigm has taken place, prompted by the omnipresent pocket calculator on the mobile phone. Today it is essential for training in the concept of numbers and to promote and train mental arithmetic, rough calculations and a relational mode of thinking (Hefendehl-Hebereker \& Schwank, 2015). This constitutes a significant contribution for applying mathematics in everyday situations and thus to achieving "SDG four". 
The following chapter will show which steps children usually take when developing their first mathematical concepts in order to finally be able to classify the missing competences or misinterpretations in children with dyscalculia.

\section{Basics in the Range of Numbers up to Ten}

Counting is often the children's first contact with the world of numbers and forms the transition between the implicit quantitative knowledge that children have already acquired in their environment and the explicit quantitative knowledge that is taught in school (Walter, 2014). The normal development of informal skills of arithmetic takes place from birth to kindergarten age and beyond. During this time, children reach various "milestones" that can be divided into three levels of competence and reflect the increasing understanding of the connections between quantities and numbers:

Competence Level I: Development of basic numerical skills related to the concept of quantity, the correct sequence of numbers and the counting procedure.

Competence Level II: Acquisition of awareness of the quantity of numbers: The sequence of numbers gains quantitative meaning, first in an imprecise number concept (little-much-very much), finally in a precise number concept (linking the sequence of numbers with an exact sequence of quantities).

Competence Level III: Understanding relationships between numbers (partial-wholeconcept) (Krajewski, 2008).

Counting is thus considered a central competence for the arithmetical learning process and forms an essential foundation for later mathematical understanding. "Quantitative and numerical prior knowledge can be seen as the most significant specific informal skill with regard to mathematical competences in the first two years of primary school" (Werner, 2009, p. 112). Longitudinal studies among kindergarten children confirm that quantity and number-related prior knowledge has a decisive influence on the later performance in primary school mathematics lessons (Gerretson, 2010; Krajewski, 2003; 2008; Walter, 2014).

Hasemann and Gasteiger (2014) also emphasize the ability of "subitizing” (p. 17), the simultaneous acquisition of up to four or five elements by three or four-year-olds. The successful counting process can be described by the counting principles described by Gelmann and Galistel in 1978:

1. The one-to-one/unambiguous principle: one numeral is assigned to each object to be counted.

2. The stable-order principle: The series of numerals has a fixed order.

3. The cardinal principle: The last named numeral indicates the number of elements of a set ("how-to-count principles").

4. The abstraction principle: The way objects are to be counted is arbitrary.

5. The order-irrelevance principle: The respective arrangement of the objects to be counted is not important for the counting result ("what-to-count principles") (Schipper, 2009, p. 75).

Hasemann (2003) presents a different model of counting competence which distinguishes five levels:

1. String level: The word order is recited mechanically like a poem. The numerals have no cardinal meaning. 
2. Unbreakable chain level: At the age of about 3.5 to 4 years, children use numerals in the correct order, but counting errors occur, for example, objects are counted twice or an object is assigned to each syllable of a numeral.

3. Breakable chain level: If random items are counted, children at about 4.5 years of age, start arranging the items while counting, for example, by pushing the items that have already been counted aside.

4. Numerable chain level: At the age of about 5 years, children know that each item is counted only once and that the latter number indicates the number of items of the set.

5. Bidirectional chain level: From about 5.5 to 6 years of age, children recognize cube pictures. Counting forwards is no longer only possible starting from one and counting backwards is also possible. With the help of counting strategies, the first word problems in mathematics can be solved (Hasemann \& Gasteiger, 2014; Schipper, 2009).

Last but not least, various aspects concerning the concept of numbers are pointed out. To begin with, children develop the cardinal number aspect, which describes the number of elements of the set. The cardinal number aspect includes the counting number aspect (the sequence of natural numbers while counting) and the ordinal number aspect (indicates the position in the ranking of an item in an ordered sequence). Other aspects like the size units aspect, operator aspect (describes the multiplicity of objects), arithmetic number aspect (numbers are used for arithmetic operations) and coding aspect (telephone numbers, post codes) only gain an importance over time (Hasemann \& Gasteiger, 2014).

All the models, developmental stages and especially the age indications mentioned are subject to changes in individual child development and can only serve as a rough guideline. The following chapter will show which difficulties children can encounter even when dealing with apparently very basic mathematical content.

\section{"What Can Be so Hard about That?"}

"One two three four five six seven eight nine ten." Children learn this catchy phrase, for example, when playing hide-and-seek, but without necessarily linking it to mathematics. As for the first approach, it is rather a period of time that one has to wait before one can start looking for playmates. Day by day, children realize that these are individual words and that they can be assigned to different objects.

The mathematician, Herrndorf (2005), recalls her first encounter with numbers as follows: "I soon understood the five correctly: 'Five', that is my little finger (of the left hand, of course, because I needed the right hand for counting). At school, I was then supposed to take two off this finger - my own five. How should I take two off my little finger? Later I had to split my little finger - the five. I still don't want to think about how to split one finger." Herrndorf (2005) also refers to the game "Mensch-ÄrgereDich-Nicht" (Ludo) to illustrate her way of counting as follows: "the others did not agree with my moving the tokens. I wanted to count the field I was standing on as well. When I noticed that their way of moving was faster, I did the same. Going faster can't be wrong."

Children often begin to accompany routine procedures or activities, such as walking over tiles or stepping stones with counting words. The author of this article also recalls a question that she could not answer at the age of about four: there were exactly eight 
large stepping stones along the access path to her parents' house. If one walked towards the house, "eight" was right at the entrance, but if one walked away from the house, "eight" was at the garden fence. The parents just did not want to believe that there were twice "eight" stones in their front yard.

F., the author's younger son, was a persistent "step counter" when he was about three years of age: "One - two - three - four - five - six - seven - eight - nine - ten". The author recognized the above mentioned "syllable trap" ("asynchronous counting", according to Hasemann (2003) at "seven". Later his range of numbers expanded to about 30, and an interesting conversation ensued one day: Together we were "counting", but already in a hurry, on the way to a doctor's appointment. F.'s order of counting was particularly faulty and incomplete: "Mum, did you notice that I left out some numbers?" - "Yes, but it doesn't matter." - "I did it on purpose, Mom, to get us faster there!"

Perhaps some readers will remember such anecdotes from their own childhood or from observing children. At least one thing becomes clear that children think differently from adults, and the logic of children is not always quite correct, but it is still remarkable and considerate (Spiegel \& Selter, 2015). In any case, despite the good will and the efforts on behalf of the teachers and learners, mathematics offers ample opportunities for misunderstandings and misinterpretations.

\section{Enhancing Misunderstandings and Misconceptions}

Sometimes common pedagogical practices even enhance children's misconceptions. Some of the pedagogical practices are as follows though the list is not exhaustive: Smallstep notion of numbers and understanding ordinal numbers.

In very young children, misconceptions occur when they develop a pattern of ordinal numbers only. This idea is supported by the way the range of numbers is structured in most current textbooks: the first school year starts by dealing with small ranges of number up to four (simultaneous understanding), up to five (using the hand) or up to six (using the cube). Gradually (number by number) the range of numbers up to ten is introduced.

Usually, additive arithmetic operations are already being performed in these small "artificial" ranges of numbers. This procedure follows the "principle of small steps" and is intended to avoid asking too much of the children. Wilhelm Grube (1816-1884) serves as a historic example. He proposed to treat numbers "monographically", that is number by number in their natural order from one to one hundred (Schipper et al., 2017). This small-step approach tempts us to think in wrong or misleading ways and reinforces the children's idea of numbers as having a rank in an infinite series of numbers. The number seven, for example, is not used to understand seven as the entire quantity, but rather, for example, the seventh stone in a row or the index finger of the left hand. This can lead to subsequent problems when expanding the number range, because the smallstep structure makes it difficult to understand the decadic structure (i.e., decimal structure) and the relationships between the numbers (Scherer \& Moser Opitz, 2010).

Put yourself in the shoes of a child who thinks like this: The range of numbers was built up in small steps, and up to number 5 the child still had a good "grip" on all additions and subtractions as they are practically in front of him/her on one hand. Now the range of numbers has been further expanded with the new number " 6 ", seven "new" possibilities to split are added $(0+6,1+5,2+4,3+3,4+2,5+1,6+0)$. With the number " 7 ", 
there are eight more possibilities to split and additionally finger calculations become more complicated because one needs both hands to calculate. Some children find this range of numbers quite challenging and become anxious because some classmates are able to solve the calculations much faster than them. In this situation, the motivated teacher might state that "children, isn't this great? We now already know the numbers up to 7 - but that's not the end - because the numbers go on infinitely. The world of numbers is infinite!". It is understandable that some children cannot see anything positive in this news. "If I have problems right now, how am I going to manage future challenges? Now I know why Dad keeps saying our family is bad at math."

The idea of an ordinal structure (number as a rank in an infinite series of numbers) is also reinforced by counting on your fingers, which is common in our culture. We usually start counting with the thumb of the left hand ("1"). Step by step, the individual fingers are bent back - the index finger is " 2 ", the middle finger " 3 ", etc. Thus, for example, for the child the index finger of the left hand represents the number " 7 ". It would be much better to present "finger packages" to the children when "pre-counting", that is after pointing a finger (" 1 "), bend it back and make a fist. At "2", both fingers are stretched out simultaneously in one movement, but then both fingers are bent back into a fist again. This process should be continued like this up to" 10 ". This slightly different way of counting emphasizes the entirety of the bent fingers more strongly. "7" is then no longer the newly added index finger, but the entirety of the stretched out seven fingers. Likewise, "7" is then to be shown, for example, as three plus four with both hands (Gaidoschik, 2018).

If a child thinks in purely ordinal terms, it is understandable that, for example, the prompt to count " 7 minus 3 " is met with incomprehension: "The index finger of the right hand minus the middle finger of the left hand? How is that possible?" The advice given by adults, that is, "you only have to count backwards" only exacerbates the problem. So the child starts counting backwards from 7: "Seven, six, five - the result is 5!" But seven minus three is not five. The adult who has good intentions may continue to "explain": "No, you can't count that last number." So the kid "reckons": "Six, five, four - the result is four." The adult is pleased that the child has now "understood" the calculation the child has learned a rule without understanding it. With the help of this strategy he or she will in the future be able to solve all calculations correctly in small ranges of numbers without knowing what he/she is actually doing. If it comes to the worst, the child's understanding is never verified, and until the range of numbers is expanded into the hundreds, the child's lack of understanding of the operation goes unnoticed. However, at least in the range of one hundred, this strategy reaches its limits - who would like to solve 74 minus 37 counting backwards?

\section{Problems Understanding Place Value}

As a result of having only an understanding of ordinal numbers, problems arise with the meaning of place value. "Ten" is not perceived as a special feature, but is only a number like many others in an "infinite series of numbers". If one now asks the child: "What comes first, 13 or 16 ", he is not able to see the analogy to 3 and 6, but must recite the numbers up to 16 to be able to answer the question. This would be comparable to the question: "What comes first: $\mathrm{N}$ or $\mathrm{K}$ ?" Here many adults also recite the part of 
the alphabet ("K $-\mathrm{L}-\mathrm{M}-\mathrm{N}$ ") to be able to answer the question. By the way, this is no cause for concern because the alphabet does not have an "inner order" like our decimal system.

For children who do not recognize essential correlations (analogies, the commutative law) when counting, every calculation must be "counted" again and again. Therefore,the process of automatizing extremely slows down. This means that the gap between children who have understood the decadic basics (the decimal structure inherent in our system) and the "counters" is widening.

Bundling tens and ones, which in the German language is made even more difficult by the fact that the numbers are pronounced in the opposite direction to the reading direction is not clear to these children when counting. For example, children do not recognize 35 as a grouping of 3 tens and 5 ones, but they consider it as a point in the infinite number sequence. This lack of understanding is also evident, for example, in the task: "What is bigger - 29 or 32?" Children answer spontaneously that 29 is bigger because it contains a 9 .

\section{Linguistic Misunderstandings}

In contrast to everyday language, which can often only be understood correctly in the respective situation and within the given frame of reference (for example, "my little brother" - meaning "my younger brother"), the language used in lessons is characterized by specific features. It is generally valid, precise, unambiguous and understandable regardless of the situation. Children have to acquire several hundred mathematical technical terms already in primary school and should be able to make abstract, generally valid, depersonalized statements ("In an addition, both summands can be swapped.") (Verboom, 2013). This subject-specific language serves as foreign language and is full of pitfalls and potential misunderstandings.

If a teacher writes the numbers 3 and 5 on the blackboard and wants to know from the children which number is larger, the typeface of the 3 is a little bit bigger than that of the 5 , so for visual learners the 3 is larger. Therefore, the actual solution is confusing for these children. The same could happen to children with even and odd numbers. The 1 is even in the typeface, while the 2 is odd. "Half of 8 " can also be answered as follows: 3 or even 0 .

\section{Use of Didactic Materials}

The use of materials is often automatically equated with "good" teaching. Educators are surprised that children do not achieve the desired success: "We have always used didactic material”.

Dealing with material does not automatically foster understanding. On the contrary, incorrect use of materials can even reinforce erroneous ways of thinking. Unstructured materials like chestnuts, glass nuggets, or marbles can be used to train counting. However, they are not suitable for arithmetic operations. Adding 17 chestnuts to 42 chestnuts does not support the understanding of the operation and is a pure counting exercise. The "calculation chains" recommended in some kindergarten manuals (i.e., chains with up to one hundred beads on which calculations can be "moved") are also not conducive to understanding the structure of the operation. 
But even appropriate material following the rules of the decimal system (one cube, tens bars, hundred plates...) does not guarantee understanding among children. It is essential that children think, while they are looking at the material and handling it, to ultimately draw abstract conclusions. This can be encouraged by asking specific questions. "Numbers as well as arithmetic operations are nothing that can be "seen" or "grasped": They must be thought and understood” (Gaidoschik, 2018, p. 43).

\section{Challenges for Sustainable Mathematics}

Whereas a few decades ago the focus was still on the rapid processing of arithmetical problems, and automated "practice" was seen as a desirable means of success. In recent decades, substantial attention has been paid to the thinking processes of children and related problematic areas that arise in initial mathematical lessons. As a result of doing research with children with arithmetic difficulties, the focus of attention in up-to-date didactics is on understanding arithmetic and getting detached from counting processes. Counting arithmetic is an important strategy before and at the beginning of the first school year and is completely adequate. Initially all children are counting calculators. "The question, however, is why some of them remain that way" (Selter, 2011, p. 3). Counting arithmetic is to be replaced by the far more effective and comprehensionbased comparative arithmetic (Gaidoschik, 2018; Schipper, 2017). According to Gaidoschik (2010), "for years, there has been agreement on this approach in the didactics of mathematics, the science of learning and the teaching of mathematics" (p. 212).

Memory recall is a strategy of a non-counting arithmetic approach: The child has already "memorized" by heart that 3 plus 4 equals 7 .

Another form is the so-called "deduction" strategy: The child does not know 3 plus 4 , but has already memorized the calculation 3 plus 3 (doublings are usually memorized more easily). With 3 plus 4 he/she thinks: If 3 plus 3 equals six, then 3 plus 4 must be one more, so 3 plus 4 equals seven. The prerequisite for a non-numerical procedure is a comprehensive concept of numbers, an understanding of relationships between numbers, and an understanding of addition and subtraction based on this (understanding of operations) (Selter, 2011).

Derivative arithmetic should be specifically promoted in the first-year mathematics lessons, because it is disadvantageous for children if they are stuck too long in counting arithmetic: Counting is error-prone, laborious, spoils the pleasure of dealing with numbers in the long run and makes it more difficult to recognize structures of numbers and correlations between calculations. In other words, "it blocks children's access to the mathematical aspects of calculating” (Gaidoschik, 2016, p. 1).

This leads to the question of how widespread counting arithmetic or deductive arithmetic is actually used in the first year of school. In Gaidoschik, Fellmann and Guggenbichler's (2010) study conducted in Austria, the calculation strategies of 139 randomly selected children from 20 randomly selected primary schools in Lower Austria were assessed. Only about 33 percent of the interviewed children had learned counting arithmetic at the end of the first school year. At the end of the first school year, about 27 percent had solved more than two thirds of the tasks in the range numbers up to 10 by counting. The question arises as to whether the expectations of the subject specific didactics were too high or whether the poor result is due to the specific teaching. It is noticeable that the teaching in the classes examined followed closely the respective text- 
books and these did not give the children any ideas for deductive arithmetic (Gaidoschik, Fellmann, \& Guggenbichler, 2015).

Another study by the same scientists, which was carried out in selected Carinthian primary schools in cooperation with the University of Klagenfurt and the University College of Teacher Education of Carinthia, provides clear evidence that teaching is indeed a key factor in the children's acquiring arithmetic strategies. The arithmetic strategies of 71 first-graders in classes where special emphasis was placed on developing and practicing deduction were surveyed in face-to-face interviews. The children's teachers had previously taken part in intensive training sessions in order to lead children away from counting arithmetic already in the first school year. Results of the study clearly show that a change in teaching has an extremely positive influence on the children's arithmetic strategies. In two out of the four classes examined, counting arithmetic in the range of numbers up to 10 was no longer used at the end of the school year. The children were able to do most of the tasks in this range of numbers by heart, in some cases deductions were made (usually very quickly). In the other two classes, the proportion of children who had left counting arithmetic completely behind them was lower (63 and 44 percent respectively). In these classes there were only three children (out of 46) for whom counting was still the predominant method of arithmetic (Gaidoschik, Fellmann, \& Guggenbichler, 2015).

The results of literary research clearly show that an up-to-date mathematical firstyear teaching makes a significant contribution to a sustainable mathematical understanding, reaching far beyond primary school. It is therefore an extremely urgent goal to adapt mathematics education in the first school year to these current literature-based findings and to focus on this desideratum in teacher training as well as in further education and training. Last but not least, it is necessary to provide teachers with suitable textbooks which are based on the results of these research findings.

Young people who are currently attending school will have to be able to cope with serious ecological, economic and social problems in the future. This requires not only entrepreneurial spirit and knowledge of the development of children but also practical skills.

The following chapter offers exemplary procedures in basic mathematics education.

\section{Proposals for Working with the Range of Numbers Up to Ten}

Counting is seen as a prerequisite for mathematical processes. Kindergarten and primary school children have very diverse previous experiences with counting. For counting, the child's environment is more suitable than for any other subject. Children are surrounded by things that can be counted. Nevertheless, counting in the school context very often takes place in the iconic form, i.e. in the textbook or on a worksheet. Most textbooks also start with a so-called "counting page", on which "strokes" are to be made for objects shown (Schipper et al., 2017). Of course, there is nothing to be said against this, but before that activity it would be more appealing for children to count concrete things. In this way, the natural need for moving around of the very young children can be met. It is essential that the teacher observes the children's activities. This allows the teacher to diagnose the children's performance, based on their background knowledge about the average development of counting and counting skills of children as presented at the beginning of this article. This diagnosis allows for rapid intervention and additional support if necessary. 
For simple action-based exercises, according to Walter (2014), Gaidoschik (2018), and Schipper et al. (2017), the teacher needs larger quantities of the same objects. These can be glass nuggets, wire balls, buttons, even foam rubber flowers in appealing boxes. At the beginning only up to ten (identical) objects in each category suffice. For children who can already count safely in larger ranges of numbers, appropriate boxes are prepared for the respective range of numbers.

- Alone or with a partner, children take a box, empty it and determine the number. The control could be done by the second child or by strokes (in a fiver structure) on the bottom of the box. The teacher has the possibility to observe the counting strategies of the children.

"At what level of counting competence according to Hasemann (2003) is the child?”

- Counting should be experienced as something exciting: A number of things are put into a counting box. The children are allowed to pick up the box, but not to open it. "Who can give the best estimate?" The winner poses the next "riddle".

"Precise number concept" according to Krajewski (2008).

- On paper plates, pictures with dots (later also numbers) are given out. Children set out the same number of materials as seen on the plate. Whether only materials of the same kind are used or whether different materials are used is a point of discussion.

"Abstraction principle" according to Gelmann and Galistel (1978).

- The children have the paper plates with a certain number of materials in front of them. They close their eyes. A "witch" (teacher, later children) changes the quantities. The change is discussed ("one more... one less... same amount").

“Competence level III" according to Krajewski (2008).

- In front of the children, a number of items is placed in a box. Now the box is shaken strongly. "How many things are in the box now?" A discussion whether the number has changed follows. Cognition: "I have added nothing to it and taken nothing away. The quantity remains the same."

"Invariance principle" according to Gelmann and Galistel (1978).

- The children are shown different cards with dots in different arrangements (for example, in a cube arrangement, in fives, in a line or jumbled). "Which numbers can you identify at a glance? Why?" It is discussed which arrangement is advantageous for quick recognition and where you have to count.

"Subitizing" according to Hasemann and Gasteiger (2014); "One-one principle after Gelmann and Galistel (1978).

- The children are to master challenging counting tasks: for example, objects are arranged in a circle and the teacher makes a counting mistake. "Why did a mistake happen?" When the objects are put in a straight line, you can count them easily. But the question is: "How many are there when you start counting from the other side?" or when the position of the objects is changed in front of the children's eyes (not the number): "How many are there now?" 


\section{Order-irrelevance principle according to Gelmann and Galistel (1978).}

- A small puppet can be used to practice counting forwards and backwards. It is passed on from child to child. If the puppet faces the child, this means: counting forwards. If the puppet is turned around, counting backwards is required. For children who do not yet have a sufficient command of the language of instruction, the following game can be carried out: at the beginning, all the children stand up, they count out loud one by one. Child number ten must sit down (but continues to count out loud without being counted himself/herself). The winner is the last child to stand. The winner is therefore determined randomly, the children do the counting up to ten with great pleasure.

"Bidirectional chain level" - level 5 according to Hasemann (2003).

Exercises of this kind enable the children to have a fun-oriented, differentiated introduction to mathematics and they form the basis for further sustainable development of mathematical skills. Once the counting to ten has been successfully accomplished, further comprehension-based exercises can be continued in the range of numbers up to ten with a holistic approach.

\section{Conclusion}

Teachers play an essential key role in teaching sustainable mathematics and therefore bear great responsibility for the success of the SDGs. Up-to-date mathematics teaching requires teachers to have a profound knowledge of mathematics, didactic knowledge, and an awareness of possible difficulties. Teachers are expected to present mathematics in ways that are likely to be different from how they themselves were taught (SaffordRamus et al., 2016).

Teachers become active co-designers of future generations through their activities. (Summer, 2019). They create settings in which pupils can transfer mathematical understanding across varied contexts and settings. The student-centered mathematical tasks allow children to develop an understanding of sustainability issues that enable them to take positive action in their daily lives (Serow, 2015). As a consequence, teachers have a key role in generating insight into the basics of sustainable development.

Quality education is at the heart of public interest and is perceived as an urgent desideratum. For mathematics teaching, this means that the children's entry into the world of mathematics must be made with the greatest care, great knowledge of content, pedagogical skills, and diagnostic competence. Children have to be equipped with mathematical skills already at an early stage of their school career which will enable them to measure and evaluate sustainability in their lives.

Based on the competent mathematics teaching, much can be achieved in terms of sustainable development and the SDG “Quality Education”. This is essential not only for basic mathematics instruction, but for the entire school and professional career of children. Clifford (1845-1879) pointed out the importance of childhood experiences in this learning process and noted that "mathematics is the gateway to science, and this gateway is so narrow and small that you can only walk through it as a small child". 


\section{References}

Akinmola, E. A. (2014). Developing mathematical problem solving ability: A panacea for a sustainable development in the $21^{\text {th }}$ century. International Journal of Education and Research. Retrieved from https://www.ijern.com/journal/February-2014/28.pdf Bka - Bundeskanzleramt. (2015). Ziele der Agenda 2030 [Objectives of the Agenda 2030]. Retrieved from https://www.bundeskanzleramt.gv.at/themen/nachhaltigeentwicklung-agenda-2030/entwicklungsziele-agenda-2030.html

BMBWF (2019). UN-Agenda 2030: Die globalen Nachhaltigkeitsziele/SDGs im Bereich Bildung [UN Agenda 2030: The global sustainability goals/SDGs in education]. Retrieved from https:/www.bmbwf.gv.at/Themen/euint/ikoop/bikoop/sdgs.html

Gaidoschik, M. (2010). Wie Kinder rechnen lernen - oder auch nicht [How children learn to calculate - or maybe not]. Frankfurt am Main: Peter Lang.

Gaidoschik, M. (2016). Aktuelle Studie: Vom Zählen zum Rechnen [Actual study: From counting to calculating]. Retrieved from http://www.recheninstitut.at/2016/10/ aktuelle-studie-vom-zaehlen-zum-rechnen/\#more-1828

Gaidoschik, M. (2018). Rechenschwäche verstehen - Kinder gezielt fördern [Understanding of arithmetic impairment - supporting children]. Hamburg: Persen.

Gaidoschik, M., Fellmann, A., \& Guggenbichler, S. (2015). Computing by counting in first grade: It ain't necessarily so. In Proceedings of the Ninth Congress of the European Society for Research in Mathematics Education CERME 9, Prague. Retrieved from https:/www.dropbox.com/sh/8ybnhniqp2r5zm7/AACvry0oJXp JHfQsX3GdxzwIa?dl=0\&preview=CERME9_TWG2_Gaidoschik_v2.pdf

Gerretson, H., Iliško, Dz., \& Fortino, C., (2010). Sustaining self-regulated students' learning through inquiry-driven mathematics and science instruction. Discourse and Communication for Sustainable Education, 1(1), 5-22.

Gerster, H.-D., \& Schulz, R. (2004). Schwierigkeiten beim Erwerb mathematischer Konzepte im Anfangsunterricht [Difficulties in acquiring mathematical concepts in basic lessons]. Freiburg im Breisgau. Retrieved from https://phfr.bsz-bw.de/ frontdoor/deliver/index/docId/16/file/gerster.pdf

Guseva, S., Dombrovskis, V., Murašovs, V., \& Iliško, Dz. (2012). Sustainability-designed learning environment for pre-school children: The case of Latvia. International Journal of Early Childhood Learning, 19(4), 15-26.

Götz, T. (2012). Langeweile im Fach Mathematik [Boredom in mathematics]. Vortrag auf der 46. Tagung für Didaktik der Mathematik [Lecture at the $46^{\text {th }}$ Conference for Didactics of Mathematics]. Weingarten. Retrieved from http://nbn-resolving.de/ urn:nbn:de:bsz:352-0-346011

Götze, D. (2015). Sprachförderung im Mathematikunterricht [Language support in mathematics lessons]. Berlin: Cornelson.

Hasemann, K., \& Gasteiger, H. (2014). Anfangsunterricht Mathematik [Initial mathematics]. Heidelberg: Springer Spektrum.

Hefendehl-Hebereker, L., \& Schwank, I. (2015). Arithmetik: Leitidee Zahl [Arithmetic: Central idea of number]. In Bruder, R., Hefendehl-Hebereker, L., SchmidtThieme, B., \& Weingard, H. G. (Eds.), Handbuch der Mathematikdidaktik [Manual of mathematical didactics]. Heidelberg: Springer Spektrum.

Krajewski, K. (2008). Vorschulische Förderung bei beeinträchtigter Entwicklung mathematischer Kompetenzen [Pre-school support for impaired development of mathematical competences]. In Borchert, J., Hartke, B., \& Jogschies P. (Eds.), Frühe Förderung 
entwicklungsauffälliger Kinder und Jugendlicher [Early support for children and young people with developmental problems]. Stuttgart: Kohlhammer.

Lindner, J. (2018). Entrepreneurship education for a sustainable future. Discourse and Communication for Sustainable Education, 9(1), 115-127.

Moser Opitz, E. (2008). Zählen-Zablbegriff-Rechnen [Counting-number concept-calculation]. Bern Stuttgart Wien: Haupt Verlag.

Safford-Ramus, K., Kumar Misra, K., \& Maguire, T. (2016). The troika of adult learners, lifelong learning, and mathematics. Hamburg: Springer.

Salite, I. (2008). Educational action research for sustainability: Constructing a vision for the future in teacher education. Journal of Teacher Education for Sustainability, $10,5-16$.

Salite, I., \& Pipere, A. (2006). Aspects of sustainable development from the perspective of teachers. Journal of Teacher Education and Training, 6, 15-32.

Scherer, P., \& Moser Opitz, E. (2010). Fördern im Mathematikunterricht der Primarstufe [Support in mathematics lessons at primary level]. Heidelberg: Springer.

Schipper, W., Ebelin, A., \& Dröge, R. (2017). Handbuch für den Mathematikunterricht, 1. Schuljahr [Handbook for the teaching of mathematics, $1^{\text {st }}$ grade]. Braunschweig: Westermann.

Schipper, W. (2009). Handbuch für den Mathematikunterricht an Grundschulen [Handbook for the teaching of mathematics in primary schools]. Braunschweig: Schroedel.

Serow P. (2015). Education for sustainability in primary mathematics education. In Taylor, N., Quinn, F., \& Eames, C. (Eds.), Educating for sustainability in primary schools. Rotterdam: Sense Publishers.

Selter, C. (2012). Prävention von Rechenschwierigkeiten [Prevention of arithmetic difficulties]. PIKAS. Dortmund. Retrieved from https://pikas.dzlm.de/pikasfiles/uploads/ upload/Material/Haus_3_-_Umgang_mit_Rechenschwierigkeiten/FM/Modul_3.1/ Sachinfos.pdf

Spiegel, H., \& Selter, C. (2015). Kinder \& Mathematik. Was Erwachsene wissen sollten [Children \& mathematics. What adults should know]. Seelze: Klett-Kallmeyer.

Summer, A. (2019). Entrepreneurship education in mathematics education for future primary school teachers. Discourse and Communication for Sustainable Education, 10(2), 89-99.

Schütky, R., Grasser, U., Haider, R., \& Holzer, N. (2017). Fachwissenschaftliche Grundlagen der Primarstufenmathematik [Scientific principles of primary school mathematics]. Graz: logomedia.

Verboom, L. (2013). “Meine Kinder können das nicht!" [My kids can't do that]. Grundschule Mathematik - Sprachförderung [Journal for Primary School Mathematics - Language Support], 39.

Walter, S. (2014). Matheabentener mit Lisa und Ali. Klasse 1. Lehrerband [Adventure in mathematics with Lisa and Ali. Class level $1^{\text {st }}$. Teachers Edition]. Hamburg: Auer.

Weber, H., \& Petermann, F. (2016). Der Zusammenhang zwischen Schulangst, Schulunlust, Anstrengungsvermeidung und den Schulnoten in den Fächern Mathematik und Deutsch [The connection between fear of school, unwillingness to go to school, avoidance of effort and school grades in mathematics and German]. Zeitschrift für Pädagogik [Journal for Pedagogy], 62(4), 551-570. 
Werner, B. (2009). Dyskalkulie - Rechenschwierigkeiten. Diagnose und Förderung rechenschwacher Kinder an Grund-und Sonderschulen [Dyscalculia - arithmetic difficulties. Diagnosis and promotion of children with dyscalculia in primary schools and special schools]. Stuttgart: Kohlhammer.

Wittmann, E. C., \& Müller, G. N. (2016). Das Zablenbuch 1. Begleitband [The numbers book $1^{\text {st }}$. Companion volume]. Wien: öbv.

Correspondence relating this paper should be addressed to Anita Summer, University Teacher College, Vienna/Krems, Austria. Email: anita.summer@kphvie.ac.at 